\title{
АНАЛИЗ СОВРЕМЕННОГО СОСТОЯНИЯ РЫНКА ЛЕГКОЙ ПРОМЫШЛЕННОСТИ В МИРЕ И РОССИИ: ПРОБЛЕМЫ И ТЕНДЕНЦИИ
}

\author{
(c) 2021 Кожина Ксения Сергеевна \\ студент, Высшая инженерно-экономическая школа \\ Санкт-Петербургский Политехнический Университет Петра Великого, Россия, Санкт-Петербург \\ E-mail: kozhina.ks@edu.spbstu.ru \\ (C) 2021 Кудрявцева Татьяна Юрьевна \\ профессор ВИЭШ, д.э.н., доцент \\ Санкт-Петербургский Политехнический Университет Петра Великого, Россия, Санкт-Петербург \\ E-mail:tankud28@mail.ru
}

Мировая лёгкая промышленность - одна из ведущих отраслей мирового промышленного комплекса. Российский рынок легкой промышленности в последние десятилетия значительно сократил производство, но все также может оставаться драйвером развития экономики страны при учете тенденций отрасли на мировом рынке. Предметом является легкая промышленность в мировой экономической системе. Цель работы - проанализировать состояние легкой промышленности в мире, определить место отечественной легкой промышленности на мировом рынке.

Ключевые слова: Легкая промышленность, внешнеэкономическая деятельность, цифровизация.

Введение. На данный момент времени ситуация на мировом рынке легкой промышленности складывается так, что большая часть производств легкой промышленности находятся в развивающихся странах, так как они имеют необходимое количество сырья (например, хлопок) и дешевую рабочую силу. Ткани импортируются развитыми странами, где впоследствии изготавливают из них готовые швейные изделия. Далее эти готовые изделия экспортируются в развивающиеся страны. Но стоит отметить, что сам производственный комплекс, принадлежащий развитой стране, может территориально располагаться в другом государстве.

Мировую легкую промышленность можно охарактеризовать следующим образом: постоянный экономический рост, который связан с ростом численности населения Земли, а также повышение уровня его благосостояния, а также покупательной способности.

Легкая промышленность является важной отраслью для стран, так как она приносит большой вклад в ВВП страны. В СССР легкая промышленность была драйвером развития страны. Но с течением времени отрасль сокращает свой рост и становится отсталой по сравнению с другим странами.

Цель исследования проанализировать современное состояние отрасли в мире и на основе сравнительного анализа выявить проблемы отечественного рынка легкой промышленности, а также определить тенденции развития отечественного рынка исходя из положительного опыта других стран.

Легкая промышленность является влиятельной отраслью для страны, так как она отличается наличием большого капитала, отличающегося быстрой оборачиваемостью. Но в России данная отрасль сталкивается с такой проблемой как техническая отсталость, а, следовательно, и низкий уровень цифровизации.

Для устранения данных негативных последствии требуются проанализировать рынок легкой промышленности как в мире, так и в России, выявить проблемы отечественного рынка легкой промышленности, определить эффективные способы их решения и тенденции развития отрасли.

Материалы и методы исследования. Для исследования были использованы материалы по внешнеэкономической деятельности России в легкой промышленности, подготовленные Инновационным центром текстильной и легкой промышленности (ИЦТЛП). Из отчета ИЦТЛП были проанализированы показатели динамики развития мирового и российского рынка легкой промышленности, такие как торговый баланс стран по отрасли, общий объем экспорта и импорта продукции легкой промышленности, которые необходимы для определения места 
отечественного рынка. Также для анализа внешнеэкономической деятельности были использованный данные по экспорту и импорту отдельных видов продукции с сайта ITC. На основе предыдущих исследований было выявлены проблемы отечественного рынка легкой промышленности, для решения которых необходимы инвестиции. Для получения информации об инвестировании в отрасль были изучена информация из базы данных EMIS. Так были проанализирована отрасль по следующим показателям:

- емкость мирового и отечественного рынка легкой промышленности;

- объем внешнеэкономической деятельности (экспорт и импорт продукции);

- соотношение валового выпуска продукции и инвестиций, вложенных в отрасль;

- соотношение валового выпуска и количества предприятий в отрасли;

- количество и долевое соотношение предприятий легкой промышленности по размеру.

Данные показатели отражают место России на мировом рынке легкой промышленности, также развитость отечественного рынка. Для работы с данными были использованы методы синтеза и анализа. Также использовались сравнительный анализ стран, методы обобщения и системного подхода.

Результаты. Легкая промышленность одна из ведущих отраслей мирового промышленного комплекса. Легкая промышленность занимает 6\% в мировом валовом продукте. За последние десять лет товарооборот легкопрома увеличился более чем в 2 раза. Стоит отметить, что за это же время в странах Евросоюза потребление продукции лёгкой промышленности увеличился на 90,5\%, в Японии - практически в 3 раза. Если рассматривать место России в мировом рынке, то только 2\% мирового товарооборота занимает лёгкая промышленность.

По данным Евромонитор, объем мирового рынка легкой промышленности в 2019 г. составил 3 трлн. долл. В целом легкая промышленность отличается постоянным экономическим ростом, который непосредственно связан с ростом населения, ростом его покупательной способности [20].

На данный момент времени лидерами в легкой промышленности являются страны, где данная отрасль является приоритетной отраслью для эффективного развития экономики страны. К таким странам относятся Китай, страны Юж- ной Америки, страны юго-Восточной и Средней Азии. Также необходимо отметить, что за последние десятилетия возникли динамично растущие новые игроки рынка легкой промышленности: страны Азии (Камбоджа, Бангладеш, Вьетнам, Индия), Африки (Египет), Латинской Америки (Гватемала, Перу, Панама), а также и Восточной Европы (Румыния, Польша, Турция). На рисунке 1 представлены торговый баланс легкой промышленности по странам лидерам поэкспорту и импорту [19].

Стоит отметить, что развивающие страны, которые имеют низкий ВВП на человека активно развивают легкую промышленность. Развитые страны в основном импортируют продукцию легкой промышленности. Также активно импортируют страны с высокоразвитой сырьевой экономикой. Страны со средним уровнем дохода частично обеспечивают себя и ближайшие регионы продукцией легкой промышленности [12].

С помощью значительной поддержки государства развивающиеся страны в легкой промышленности стремительно развиваются, что впоследствии сказалось на перераспределении производственных сил, предполагающие, что производства продукции легкой промышленности перенеслись в страны с дешевой рабочей силой. Развивающиеся страны занимают значительные доли в мировом производстве во многом в сегментах, которые менее технологичны.

Рассмотрим страны, в которых в 2018 году в легкую промышленность были вложены инвестиции в наибольшем объеме. На графике (рисунок 2) представлено соотношение инвестиций в легкую промышленность и валовый выпуск продукции [21].

Исходя из него можно сделать вывод, что Индонезия является лидером по инвестициям в легкую промышленность, соответственно валовый выпуск продукции значительно выше, чем в других странах. Инвестиции в легкую промышленность очень сильно отразились на выпуске продукции в 2019 году, который вырос практически на 20 млрд. дол. [16].

Стоит отметить, что инвестиции не везде оказали положительное влияние на выпуск продукции. В большей части стран на следующие года после вложения инвестиций валовый выпуск продукции сократился.

Если рассматривать Россию, то в 2018 году в легкую промышленность было инвестировано 0,15 млрд. дол., а валовый выпуск продукции со- 


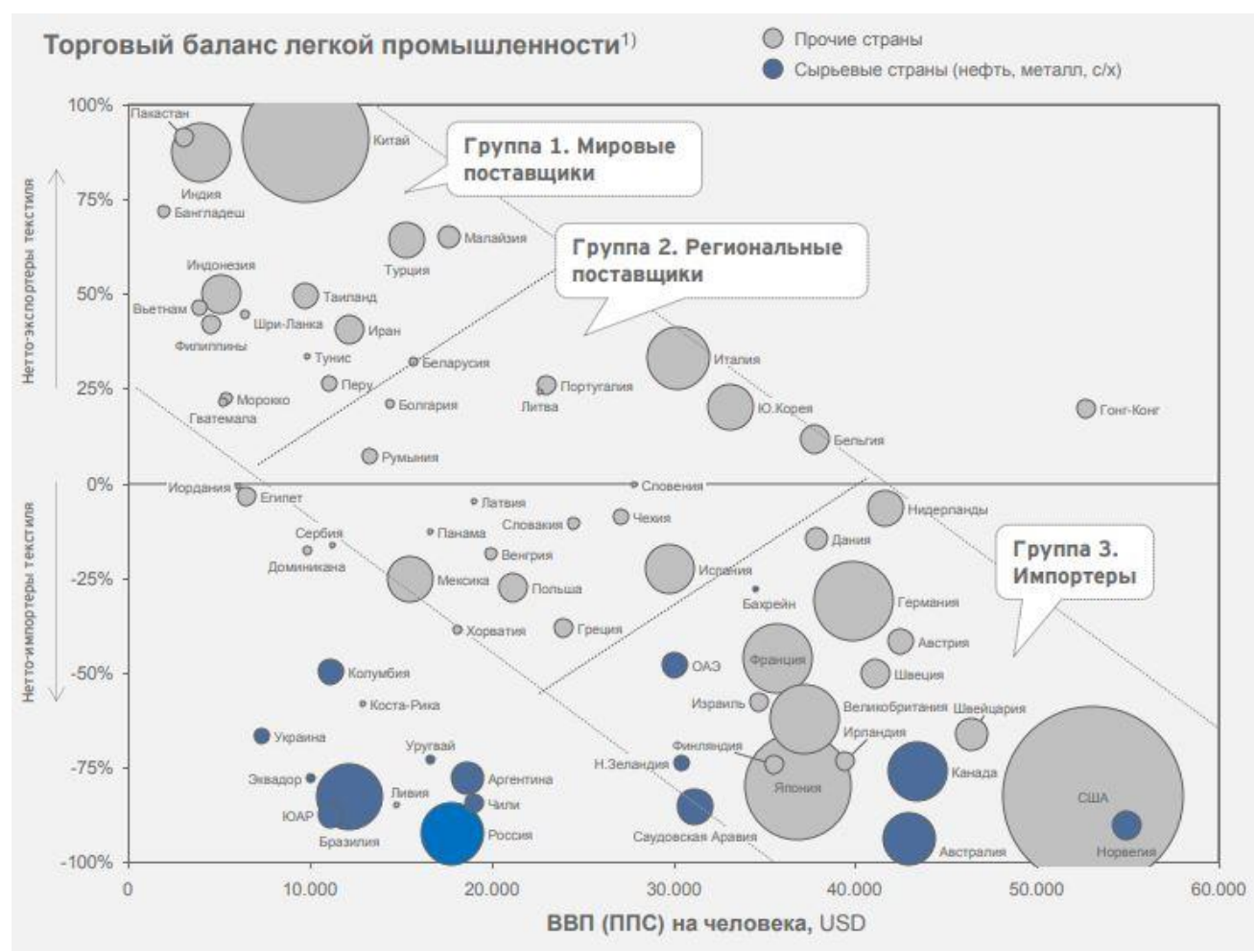

Риунок 1. Торговый баланс легкой промышленности по странам

Соотношение инвстиций в легкую промышленость и валовый выпуск продукции

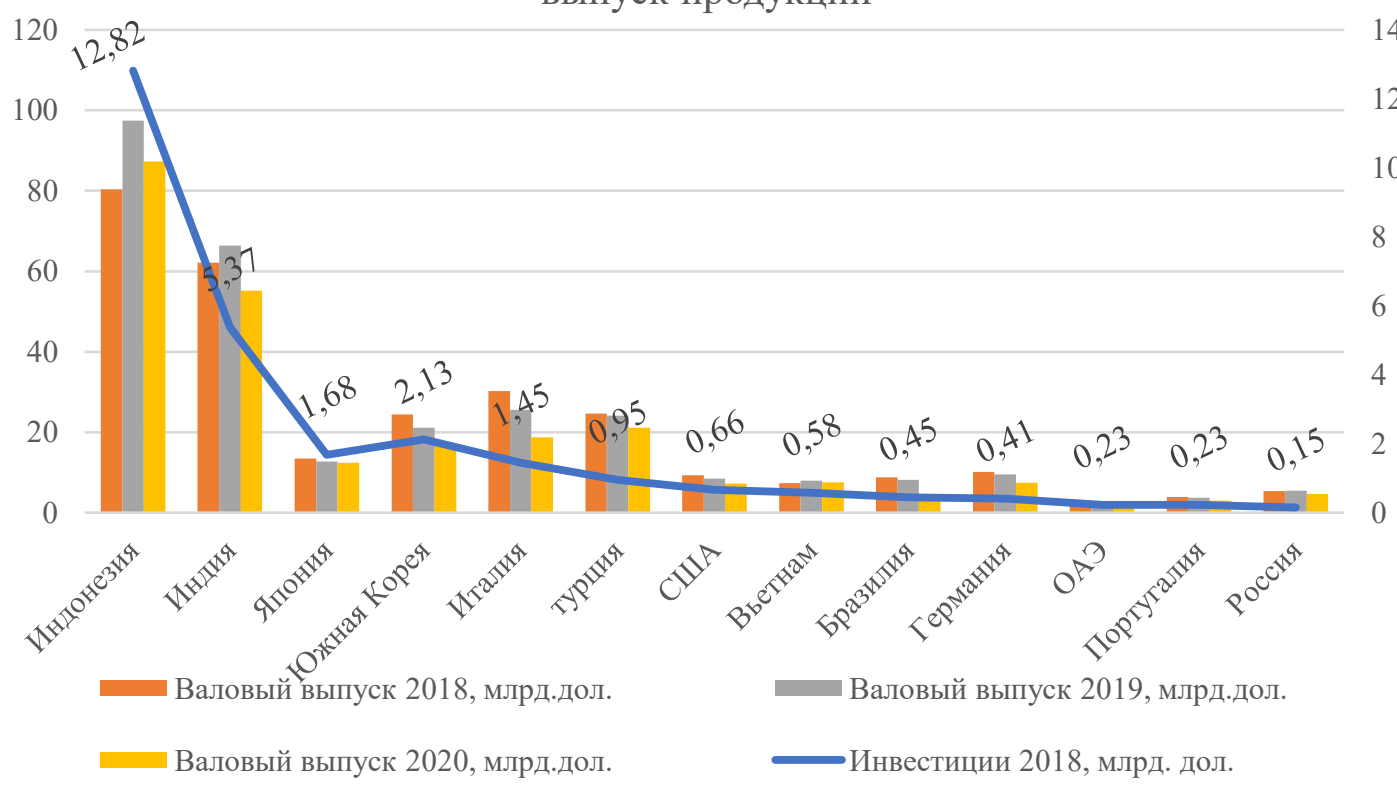

Риунок 2. Соотношение инвестиций и динамики валового выпуска 
ставил 5,39 млрд. дол. В 2019 году валовый выпуск незначительно вырос и составил 5,43 млрд. дол., а в 2020 году сократился до 4,66 млрд. дол. [17].

Также рассмотрим соотношение количества организаций легкой промышленности и валовый выпуск в 2018 году (рисунок 3).

По графику можно отметить, что, имея 8 предприятий легкой промышленности, Индонезия является лидеров по выпуску продукции. На каждую компанию в среднем выходит по 10 млрд. дол. валового выпуска. Россия показывает, что валовый выпуск продукции легкой промышленности 2018 году составил 5,39 млрд. дол. при том, что предприятий, занимающихся производством одежды, составило 2209. Каждая организация в среднем выпускала продукции на 2,4 млн. дол. Но обратная связь между валовым выпуском и количеством предприятий не подтверждают остальные страны. Например, практически одинаковый валовый выпуск продукции в 2018 году был у Южной Кореи и Турции (24 млрд. дол.), но при этом организаций, специализирующихся производстве одежды, в Южной Корее составило 53, а в Турции 407.

Емкость мирового рынка легкой промышленности, по различным оценкам, составляет \$1,1-1,3 трлн. дол. (69,3-81,9 трлн. руб.). Объем рынка легкой промышленности России в 2018 г. составил 1,8 трлн. руб. В стоимостном выражении рынок вырос на 11\% по сравнению с 2017 г. Основным фактором роста стало увеличение импорта на $18 \%$. По оценкам экспертов объем незаконного товарооборота в 2018 г. составил порядка 30\% от общего объема импорта и производства, оставшись на уровне 2017 г. Доля незаконного товарооборота в общем объеме рынка составляет порядка 24\%. По оценкам экспертов емкость рынка легкой промышленности в России в 2019 году составило около 3 трлн. руб., соответственно, доля легкой промышленности в обрабатывающем производстве составила $1,1 \%$, а серый рынок в легпроме в 2019 г. составил $25 \%$ [11].

Российский экспорт на мировом рынке крайне мал и составляет $0,08 \%$ в 2009 г. и $0,13 \%$ в 2019 г. И несмотря на прогнозируемый долгосрочный рост, к 2030 г. доля экспорта на мировом рынке составит только 0,19\%. В 2019 году объем экспорта вырос на 4,5\% по сравнению с 2018 годом и составил 1,5 млрд. долл. США. В основном экспортируют одежду (375 млн. долл.) и обувь (231 млн. долл.), что в сумме составляет $41,7 \%$ структуры российского экспорта [10].

Импорт России текстиля и обуви по итогам 2019 года составил 15,1 млрд. долл. США, что больше на 1,8\% к 2018 году. В период 2010-2019 годов импорт продукции легкой промышленности можно охарактеризовать низкой динамикой со среднегодовыми темпами менее 1\% [7].

На рисунке 4 представлен результаты анализа экспорта и импорта одежды за 3 квартала 2020 года по данным сайта TradeMap [15].

По полученным результатам, стоит сделать вывод, что основным направлением экспорта одежды являются Казахстан и Беларусь. Основными импортерами одежды являются Китай, Бангладеш [4].

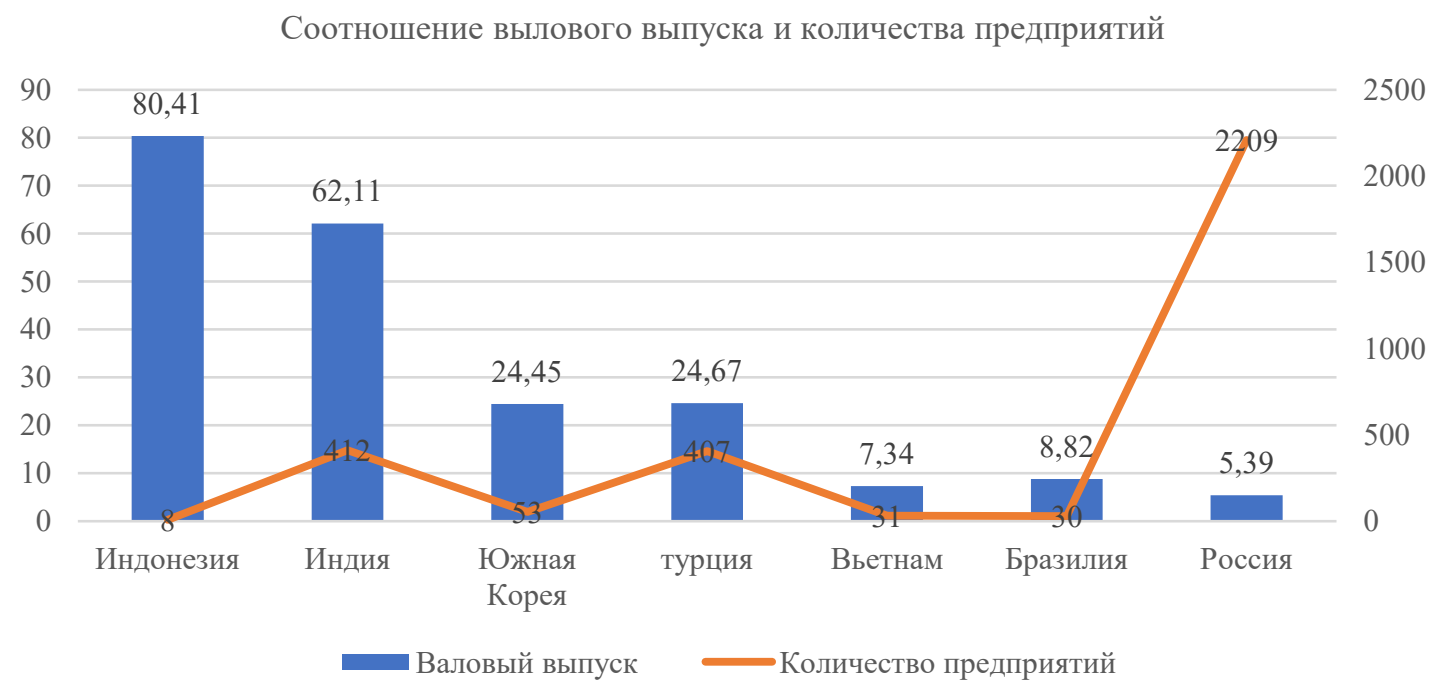

Риунок 3. Соотношение валового выпуска и количества предприятий легкой промышленности по станам в 2018 году 

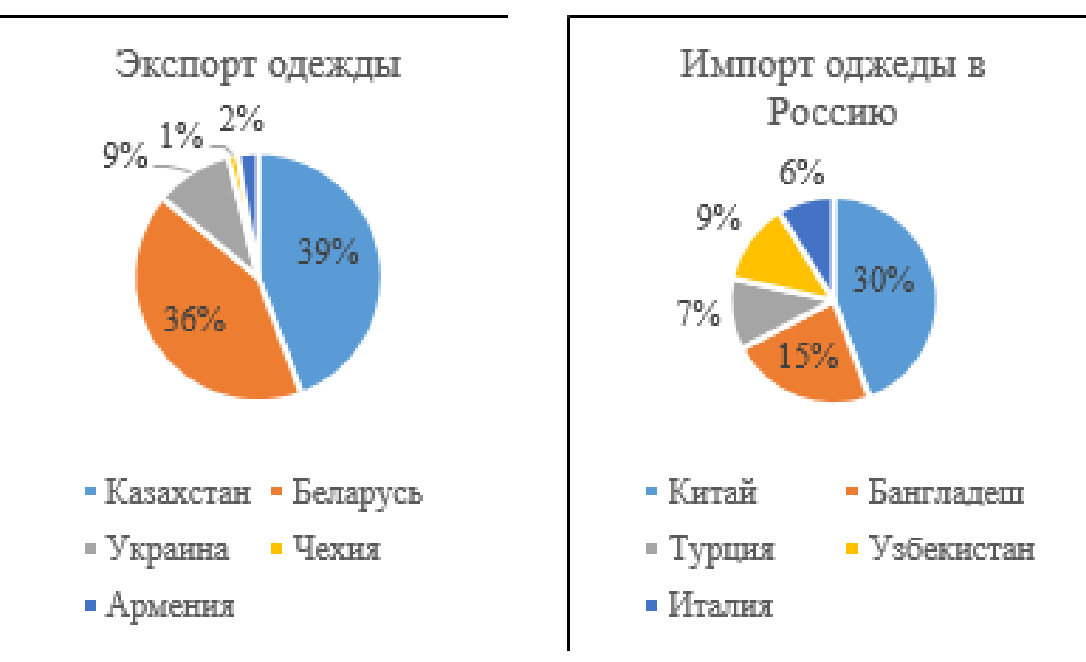

Рисунок 4. Направления экспорта и импорта товаров легкой промышленности

По данным ОКПД 2 за 2019 год в легкой промышленности было зарегистрировано более 22 тыс. предприятий. Из них 60\% производят одежду, 30\% - текстиль и $10 \%$ - кожу и изделия из кожи. По данным анализа 20,5 тысяч предприятий, 93\% из них - микропредприятия (таблица 1). Наибольшая концентрация предприятий легкой промышленности находится в Москве, Санкт-Петербурге, Московской и Ивановской областях [6].

Как уже отмечалось ранее, Россия на мировом рынке занимает небольшую долю, так как имеет ряд проблем, связанных с отсталостью от мировых лидеров [3]. К таким проблемам можно отнести:

- техническую и технологическую отсталость легкой промышленности от зарубежных стран, которая отражена в высокой материалоемкости, энергоемкости и трудоемкости производства (производительность отечественных предприятий легкой промышленности в среднем на 20\% ниже среднего мирового уровня);

- достаточно низкий уровень инновационной и инвестиционной деятельности в отрасли, отражаемый в низкой конкурентоспособности отечественных товаров;

- высокая доля импорта сырья и оборудо- вания, послужившая причиной роста товарной зависимости государства от зарубежных стран;

- социальная и кадровая проблема, заключающаяся в нехватке высококвалифицированных специалистов, управленческих кадров, основных и вспомогательных рабочих по всем технологическим переходам $[8,13,18]$.

Решение проблемы повышения эффективности производства продукции легкой промышленности многие предприятия связывают с перспективами цифровизации процессов и производств. Но на данный момент цифровизация осуществляется частично, и в основном путем внедрения автоматизированных раскройных комплексов, САПР одежды, АСУП для подготовки производственного процесса [5].

K сожалению, в России технологическое и техническое отставание препятствует развитию цифровизации в отрасли. К ним относят рыночные сбои, связанные с неквалифицированной рабочей силой, неразвитую инфраструктуру ИКТ, а также проблемы отсутствия прозрачности данных, прав интеллектуальной собственности и кибербезопасности. Данные проблемы труднопреодолимы без участия государства, в связи с чем для развития легкой промышленности государство должно реализовать ряд мер

Таблица 1. Количество и долевое соотношение предприятий легкой промышленности по размеру

\begin{tabular}{|c|c|c|}
\hline Предприятия & Количество, шт. & $\begin{array}{c}\text { Доля в общем количестве } \\
\text { предприятий, \% }\end{array}$ \\
\hline Микропредприятие & 10039 & 93,7 \\
\hline Малые предприятия & 569 & 5,3 \\
\hline Средние предприятия & 70 & 0,7 \\
\hline Крупные предприятия & 41 & 0,4 \\
\hline
\end{tabular}


поддержки по развитию цифровизации отрасли, что успешно сработала в развитых странах [2].

На данный момент в России осуществляется три вида мер поддержки легкой промышленности: финансовая поддержка, Регуляторная поддержка и продвижение. Финансовая поддержка предполагает различные выплаты организациям для их развития. К ним относят займы ФПР, субсидии, поддержка РЭЦ, механизмы льготного лизинга, корпоративные программы повышения конкурентоспособности. Регуляторная поддержка выделяет два направления: меры таможенно-тарифного регулирования и создание системы маркировки товаров. В рамках продвижения государство организовывает семинары для экспертов, дает возможность участия в международных конгрессно-выставочных мероприятиях, определяет бизнес-миссии [14].

За последние пять лет вложенные субсидии в отрасль дали экономический эффект. В 2015 году производство продукции легкой промышленности увеличилось на 33,4\%, но затем темпы прироста сократились. Средний темп роста объем производства продукции лёгкой промышленности составил 5\% в год в период с 2015 по 2020 года. Из этого можно сделать вывод, что меры государственной поддержки оказали положительное влияние на легкую промышленность. Но стоит отметить, что меры государственной поддержки имеют точечный характер, то есть направлены на отдельные подотрасли, которые не всегда являются локомотивами отрасли.

Тем не менее легкая промышленность всегда была трудоемкой отраслью, где ранее требовался ручной труд, а сейчас он заменяется на высокотехнологичных роботов, которые в свою очередь, ускоряют темпы работы, сокращают количество бракованной продукции, повышают качество продукции. Кроме того, современные технологии соответствуют следованию одной из мировой тенденции такой как кастомизация продукции [9].

Также можно выделить следующие тенденции на мировом рынке легкой промышленности:

- цифровое проектирование продукции и моделирование технологических процессов, что помогает отследить и внести все необходимые изменения в производство продукции (от идеи до эксплуатации);

- использование «аддитивных» технологий;

- использование Big Data для анализа по- требностей потенциальных потребителей;

- автоматизация и интеграция производственных и управленческих процессов в единую систему;

- использование технологий для перевода документооборота в электронный формат, автоматизации процесса заказа расходных материалов и поставки готовой продукции потребителю [1].

Выводы. Мировой рынок легкой промышленности растет с каждым годом. Лидерами в данной отрасли являются Китай, страны Южной Америки, страны юго-Восточной и Средней Азии. Если рассматривать страны по развитости, то развивающие страны с дешевой рабочей силой активно развивают лёгкую промышленность, развитые страны импортируют продукцию легкой промышленности, а станы со средним уровнем дохода только частично обеспечивают себя продукцией, а также могут обеспечивать ближайшие регионы. Объем мирового рынка легкой промышленности в 2019 году составил Зтрлн.долл.

Россия на данный момент занимает небольшую долю от объема мирового рынка. Такая ситуация была не всегда, так как 2-3 десятилетия назад легкая промышленность была драйвером развития страны.

В России преобладает импорт над экспортом продукции легкой промышленности. Также четверть рынка занимает незаконный товарооборот, что негативно сказывается на состояние отрасли в стране. Кроме того, отечественный рынок легкой промышленности имеет ряд проблем, предполагающие технологическую отсталость от мировых лидеров, низкую инвестиционную привлекательность, нехватка высококвалифицированного персонала. Решение этих проблем организации видят в оцифровке своих производств. Но самостоятельно организации не смогут полностью совершить переход в цифровую среду, поэтому государство предлагает комплекс мер по поддержке отрасли. Данная политика государственной поддержки легкой промышленности имеет положительный эффект в других странах.

В современных условиях легкая промышленность вновь может стать драйвером экономики, что отражено в Программе стратегического развития легкой промышленности РФ до 2025 года. В то же время анализ современного состояния легкой промышленности показал, что она испы- 
тывает значительное число проблем, негативно влияющих на ее экономический рост и финансовую устойчивость. В связи с этим необходимо внедрять в предприятия легкой промышлен- ности цифровые технологии, такие как ПО для проектирования и моделирования технологического процесса, аддитивные технологии, Big Data и другие технологии.

\section{Библиографический список}

1. Баллыев С.Б., СукоркинаА.В., ШарифуллинФ.С.Перспективы развития инновационных технологий на предприятиях легкой промышленности // Молодежь и XXI век - 2019. 2019 г.

2. Гаджибекова И.А. Легкая промышленность Дагестана - проблемы развития // Современный менеджмент: теория, методология и практика. 2019.

3. Гончаренко Д.В., Картамышаева К. В. Легкая промышленность в аспекте устойчивого развития // Международный журнал гуманитарных и естественных наук, 2017, № 12.

4. Горбашко Е.А., Леонов С. А., Малевская-Малевич Е.Д. Влияние цифровизации на обеспечение качества в текстильной промышленности // Известия высших учебных заведений. Технология текстильной промышленности, 2019

5. Дубова Н. Автоматизация: от идеи до утилизации // Открытые системы 2018 г., № 6.

6. Дорофеева А.М., Текстильная и легкая промышленность как сферы государственного регулирования // Будущее науки - 2020, 2020 г.

7. Зейналов С. С. Легкая промышленность Азербайджана и международный инвестиционный опыт // Экономика и предпринимательство, 2019 г.

8. Ибрагимова И. С. Проблемы долгосрочного роста текстильной и швейной промышленности России // Вестник Пермского университета. Серия: Экономика. 2019 г.

9. Истомина Е.А. Оценка трендов цифровизации в промышленности // Вестник Челябинского государственного университета, 2018. № 12. С.108-116

10. Итоги развития легкой промышленности России 2015-2019 гг. Перспективы отрасли в 2020-2025 гг.// Инновационный центр текстильной и легкой промышленности 2019 г.

11. Концепция развития легкой промышленности // Минпромторг России, 2017 г.

12. Кудрявцева Т.Ю., СхведианиА.Е.Эконометрический анализ региональной отраслевой специализации (на примере обрабатывающей промышленности России) // Экономический анализ: Теория и практика, 2020 г.

13. Куликова О. М. Легкая промышленность России: проблемы и ключевые тенденции развития // Тренды развития современного общества: управленческие, правовые, эконмические и социальные аспекты, 2018 г.

14. Мелая Т.Г.Инновационные технологии в современном дизайне костюма // Фундаментальные исследования, 2017 г., № 2

15. Минпромторг подводит итоги 2019 года // Текстильные новости, 2020 г.

16. Натаова Н.Ю., Термюк М.Ш. Анализ мирового рынка товаров отрасли легкой промышленности: современное состояние // Наука XXI века: проблемы, перспективы, информационное обеспечение, 2018 г.

17. Обзор рынка текстильной промышленности // Энциклопедия российского бизнеса, 2018 г.

18. Пак В.Г. Дефицит высококвалифицированных кадров как ключевая проблема промышленности России // Передовые технологии России 2016 г.

19. Саляхова Н. С. Легкая промышленность как многопрофильный производственный комплекс // Молодежь и наука: шаг к успеху, 2019 г.

20. Abdikerimova G.I., Nurasheva K. K., Umbetaliyev N.A., Bekmanova G. Light industry of the republic of Kozakhstan: risks, problems and ways of their resolution // Proceedings of Higher Education Institutions. Textile Industry Technology. 2020. № 4

21. Zaitsev Y.O., Ponomariov, O.S. KrasnorutskiyO.O., SlobodianykA.M. Analysis of the Modern Monitoring Implementation Methods as the Main// International journal of advanced science and technology, 2020 